\title{
Prognostic significance of coronary flow reserve assessed by MR flow measurement in the coronary sinus in patients with hypertrophic cardiomyopathy
}

Yasuyuki Shiraishi ${ }^{{ }^{*}}$, Tatsuro Ito $^{2}$, Masaki Ishida ${ }^{2}$, Motonori Nagata ${ }^{2}$, Kakuya Kitagawa $^{2}$, Hiroshi Nakajima ${ }^{3}$, Kaoru Dohi ${ }^{3}$, Masaaki Ito ${ }^{3}$, Hajime Sakuma²

From 16th Annual SCMR Scientific Sessions

San Francisco, CA, USA. 31 January - 3 February 2013

\section{Background}

Previous studies using positron emission tomography demonstrated that decrease in global coronary flow reserve (CFR) predisposes to major cardiac events in patients with coronary artery disease. However, the value of MR assessment of CFR has not been clarified for predicting future cardiac events in hypertrophic cardiomyopathy (HCM). The purpose of this study was to evaluate a prognostic significance of CFR measurement in the coronary sinus in patients with HCM.

\section{Methods}

Fifty-three patients with HCM underwent MR flow measurements in the coronary sinus during adenosine stress and in the resting state, cine MRI and late gadolinium enhanced (LGE) MRI between 2005 and 2008. CFR was calculated as the ratio of hyperemic blood flow divided by resting blood flow. After exclusion of 13 patients who had impaired LV systolic function on cine MRI (LVEF $<50 \%$, $\mathrm{n}=11$ ) or congestive heart failure (NYHA class III-IV, $\mathrm{n}=2$ ), 40 patients with a mean age of $62.6 \pm 10.7$ years were followed for a mean duration of $4.8 \pm 1.9$ years. Unfavorable outcomes were defined as cardiovascular death, unplanned cardiovascular hospital stay, and sustained ventricular arrhythmias requiring the implantation of cardioverterdefibrillator.

${ }^{1}$ Cardiology, National hospital organization Tokyo medical center, Tokyo, Japan

Full list of author information is available at the end of the article

\section{Results}

Thirteen $(33 \%)$ of 40 patients had unfavorable outcomes ( 1 sudden cardiac death, 1 death from worsening congestive heart failure, 9 admissions for worsening heart failure, and 2 sustained ventricular arrhythmias). Reduced CFR in response to adenosine was strongly associated with unfavorable outcomes (Figure 1). Ten of 17 patients (59\%) with reduced CFR of $<2.4$ had unfavorable outcomes, while only 3 events were observed in 23 patients with CFR of $>2.40$. In a stepwise multivariable Cox regression model

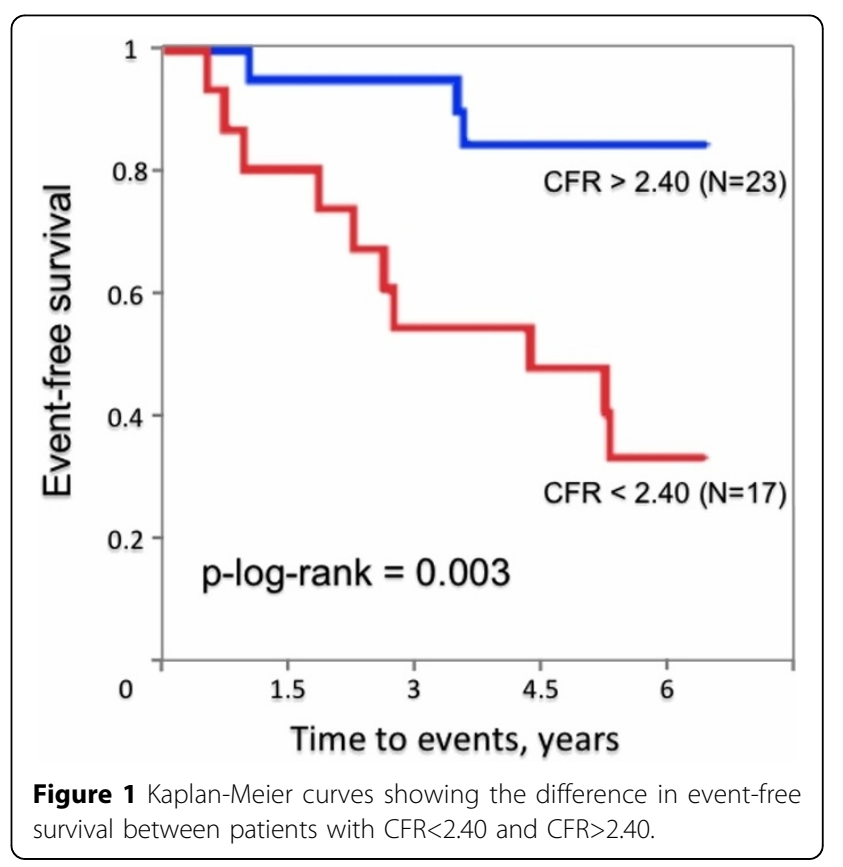


including age, CFR, LV mass index, left atrial diameter, the presence of LGE, LV outflow tract obstruction, atrial fibrillation and familial history, reduced CFR was an independent predictor of unfavorable cardiac outcomes with a hazard ratio of 5.96 (95\% CI, 1.49 to $23.80 ; \mathrm{P}=0.012)$.

\section{Conclusions}

Reduced CFR assessed by MR flow measurement in the coronary sinus is a strong, independent predictor of unfavorable cardiac outcomes in HCM patients with preserved LV systolic function.

\section{Funding}

Departmental research funding.

\section{Author details}

${ }^{1}$ Cardiology, National hospital organization Tokyo medical center, Tokyo, Japan. ${ }^{2}$ Radiology, Mie university hospital, Tsu, Japan. ${ }^{3}$ Cardiology, Mie university hospital, Tsu, Japan.

Published: 30 January 2013

- Convenient online submission

- Thorough peer review

- No space constraints or color figure charges

- Immediate publication on acceptance

- Inclusion in PubMed, CAS, Scopus and Google Scholar

- Research which is freely available for redistribution 